\title{
Spanish multicenter real - life registry of retrievable vena cava filters (REFiVeC)
}

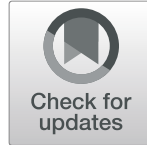

Miguel A. De Gregorio ${ }^{1 *}$, Jose A. Guirola', Jose Urbano², Ignacio Díaz-Lorenzo ${ }^{3}$, Jose J. Muñoz ${ }^{4}$, Elena Villacastin ${ }^{5}$, Antonio Lopez-Medina ${ }^{6}$, Ana L. Figueredo ${ }^{7}$, Javier Guerrero ${ }^{8}$, Sergio Sierre ${ }^{9}$, Javier Blazquez Sanchez ${ }^{10}$, William T. Kuo ${ }^{11}$ and David Jimenez ${ }^{12}$

\begin{abstract}
Background: The treatment of venous thromboembolic disease the treatment of choice is systemic anticoagulation. However, the interruption of the inferior vena cava with filters has been recommended when anticoagulation fails or there is a contraindication. Due to the rising inferior vena cava filter (IVCF) complications, physicians are encouraged to retrieve them when there is no longer recommended. In daily practice, it may be a difficult close follow-up of these patients. In this study, the primary objective was to evaluate the IVCF retrieval rate of all implanted filters in a Spanish registry. Secondary objectives were to analyze the causes of failed retrieval, procedure-related complications, and outcomes at a 12-month follow-up.

Results: Three hundred fifty-six vena cava filters were implanted in 355 patients. The types of filter were: Gunther Tulip (Cook Medical) 160 (44.9\%), Optease (Cordis) 77 (21.6\%), Celect (Cook Medical) 49 (13, 7\%), Aegisy (Lifetech Scientific) 33 (9.2\%), Option ELITE (Argon Medical devices) 16 (4.4\%), Denali filter (BD Bard) 11 (3.08\%), ALN filter (ALN) 10 (2.8\%).

Removal was achieved in 274/356 (76,9\%). eighty-two $(23,1 \%)$ IVCF were not retrieved due to the following: 41 (11, $5 \%)$ patients required ongoing filtration, 24 IVCF (6,7\%) patients died before retrieval, and 17 (4,7\%) impossibility of retrieval because of a tilted and embedded filter apex. There were no major complications observed.

Conclusions: The global retrieval rate of IVCF was achieved in 76.9\%, and the adjusted retrieval rate was of $94.15 \%$ with no major complications. IVCF tilting was associated with failure of filter removal in less than $5 \%$ of cases. This study demonstrates that the retrieval procedure of IVCF is controlled by the clinician and not by the interventional radiologist.
\end{abstract}

Keywords: Inferior vena cava filters, Retrievable filters, Venous thrombotic disease (VTD)

\section{Background}

Venous thromboembolic disease (VTD) is a serious disease that affects $1-2$ per 1000 of European citizens (Monreal et al. 2015). VTE includes acute deep vein thrombosis (DVT) and pulmonary embolism (PE). The treatment of choice in VTD is therapeutic systemic anticoagulation which includes the treatment with: heparin, low weight heparins, warfarin, acenocoumarol

\footnotetext{
*Correspondence: mgregori@unizar.es

'Hospital Universitario Lozano Blesa, Universidad de Zaragoza, Zaragoza, Spain

Full list of author information is available at the end of the article
}

or the new oral anticoagulants (apixaban, endoxaban, rivaroxaban, or dabigatran) (Pattullo et al. 2016). When anticoagulation fails or is contraindicated, inferior vena cava interruption is recommended, historically it was performed via surgery, and over the past few decades, the endovascular procedure is the standard of choice using various implantable filtration devices with almost in all devices with a retrievable option (Yunus et al. 2008).

Until the publication of $\mathrm{H}$ Decousus, et al. in 1998 (Decousus et al. 1998), even with little clinical evidence, no one questioned the usefulness of inferior vena cava 
filter (IVCF) for the prophylaxis and treatment of VTD (Proctor and Greenfield 2008; Athanasoulis et al. 2000; Stein et al. 2004; Dalen and Stein 2013). It was Decousus, et al. and the PREPIC study (PREPIC Study Group 2005) that demonstrated that IVCF represents a potential benefit with protection against life-threatening pulmonary embolism in a short-term; however, with a higher risk of symptomatic DVT in a long-term without mortality difference at 8 years of follow-up. Therefore, the use of IVCF decreased in Europe (PREPIC Study Group 2005; Reddy et al. 2017; Wadhwa et al. 2017). The arrival of new retrievable IVCF increased the indications for filter placement, to provide protection against $\mathrm{PE}$ in the short-term while avoiding the long-term DVT risks by removing the filter in a short period. In the past decade, it has encountered a rising complication in the IVCF placement reported in the United States, MAUDE database (Amendola and Acosta 2016), that resulted in a Safety Alert issued by the FDA in 2010 (Morales et al. 2013). This safety alert encourages physicians and clinicians responsible for the care of patients with IVCF, to consider removing the filters when there was no longer an indication of inferior vena cava interruption. (Amendola and Acosta 2016; Food and Drug Administration 2011) However, in daily clinical practice, it may be difficult to follow patients closely and prompt filter removal.

We present the results of a multicenter prospective registry involving 15 tertiary Spanish hospitals using a protocol to facilitate close patient follow-up for prompt filter removal.

The primary objective of this study was to evaluate all the inferior vena cava filter (IVCF) retrieval rate of implanted IVC filters. Secondary objectives were to analyze the causes of failed retrieval, procedure-related complications, and outcomes at a 12-month follow-up.

\section{Material and methods}

The SERVEI-REFiVeC (Registro Español de Filtros en Vena Cava Inferior) Registry is a prospective multicenter study endorsed by the Spanish Society of Vascular and Interventional Radiology (SERVEI) and by the Zaragoza University. This Registry received institutional review board approval in May 2016 (CP-CI number PI16 / 0142), and the study was registered in Clinical Trial Gov (NCT02757001). The registry was open from 01 to 0416 until 01-04-18. The form was designed by the research group (GITMI) of the University of Zaragoza.

An electronic patient report form was specifically designed for this registry and hosted on the Spanish Society of Vascular and Interventional Radiology (SERVEI), webpage (Sociedad Española Radiología Intervencionista (SERVEI), estudios y registros 2020).

This was open to all members of SERVEI society, after identification and acceptance by the study principal investigator (PI), and all of the interventional radiologists (IRs) had at least 5 years in experience for the placement and retrieval of IVCF. Over 2 years, all patients with an IVCF implantation were consecutively enrolled by an electronic registry. The following data were gathered: demographics, VTE risk factors, filter placement indications, IVCF type, filter dwell time, number of retrieval attempts and retrieval outcome (Table 1). The follow-up was carried out at least 1 year and determined if an appearance of PE or DVT. In case of clinical suspicion of PE or DVT, pulmonary CT angiography was performed for the suspicion of PE or ultrasound- Doppler for DVT. Complications were classified according to CIRSE standards (Filippiadis et al. 2017). The study was conducted following the "Strengthening the Reporting of Observational Studies in Epidemiology (STROBE) Statement: guidelines for reporting observational studies (von Elm et al. 2007).

\section{Statistical analysis}

We used chi-square or Fisher's exact tests to compare categorical data between groups. We used the Shapiro-Wilk test to assess continuous data for a normal distribution.

We used two-tailed unpaired t-tests to compare parametric continuous data between two unpaired groups, and we used the Mann-Whitney $U$ test for non-

Table 1 Registry form. Data points included in the registry

\begin{tabular}{ll}
\hline Identification & Number \\
& Sex \\
& Age \\
& Risk factors \\
& Filter indication \\
& Access \\
& Filter type \\
Technical data & Filter implantation date \\
& $1,2,3 \ldots$ \\
Recovery attemps & Yes /NO \\
Death before recovery & Yes /NO \\
Anticoagulant treatment & Yugular vein (R/L) \\
Recovery access & Femoral vein (R/L) \\
& Others \\
& Set recommended by the \\
manufacturer \\
Recovery with manufacturer & Snare, ballooms, cocodrile \\
recommended set & clips, grasping \\
Recovery with other maneuvers & Tilt, leg penetration, fibrosis, \\
thrombosis, death, others & $3,6,12$ months \\
Cause of inability to filter recover & Recurrence pulmonary \\
embolism, other causes
\end{tabular}


parametric data comparisons. We conducted statistical analyses using STATA version 13.1 (STATA Corp, College Station, Texas). All hypothesis tests were two-sided, with a significance level of 0.05 .

The registry was designed to enroll at least $200 \mathrm{pa}$ tients with IVCF and recorded clinical follow-up at least one year after recovery, evaluating possible episodes of recurrent PE, DVT or possible death of the patient.

\section{Results}

\section{Demographics}

From April 2016, until April 2018, three hundred fiftysix vena cava filters were implanted in 355 patients (1 patient received two filters for having double vena cava). The mean age was $59.7 \pm 13.7$ years (range 89-19 years. One hundred and eighty-two $(51.1 \%)$ patients were men and $174(48.8 \%)$ women, 15 Spanish tertiary hospitals participated in the REFiVeC registry. The average IVCF implantation in each center was $23.6 \pm 25.9$ (range 1011 IVCF). The types of filter used in the registry were: Gunther Tulip (Cook Medical) 160 (44.9\%), Optease (Cordis) 77 (21.6\%), Celect (Cook Medical) 49 (13, 7\%), Aegisy (Lifetech Scientific) 33 (9.2\%), Option ELITE (Argon Medical devices) 16 (4.4\%), Denali (BD Bard) 11 (3.08\%), ALN filter (ALN) 10 (2.8\%).

\section{Indications}

VTD risk factors included immobilization in 197 (55.4\%), neoplasm in 55 (15.4\%), recent surgery in 46 (12.9\%), history of VTE in $35(9.8 \%)$ and contraceptive use in $24(6.7 \%)$. Of the patients who required a vena cava filter, 309 had one risk factor for VTD, 43 had two risk factors, and 4 had more than two risk factors. The main indications for IVCF were: presence of VTE with contraindication to anticoagulation in 188 (52.8\%), Prevention in high-risk patients with DVT in 120 (33.7\%), (in this case, 54 patients suffered massive PE, 49 suffered iliofemoral DVT and 17 COPD and DVT), and recurrent PE despite anticoagulation in 48 (13.4\%) (Table 2).

\section{Access and imaging}

The access route used for the implantation of the filter was: the right internal jugular vein in 180 cases (50.5\%), the right femoral vein in 148 (41.5\%), the left femoral vein in $25(7.02 \%)$ and the left internal jugular vein in 2 $(0.5 \%)$ cases. Cavography was performed in all patients during filter removal, 260 (73.03\%) patients underwent abdominal computed tomography before IVCF retrieval. The indication of abdominal CT was to facilitate withdrawal (knowing the inclination, the presence of thrombosis or migration) and was performed on the same day before the IVCF retrieval. The abdominal CT, 185 (71.1\%) patients had normal findings regarding the position and tilt of the filter; in $41(15.7 \%)$ patients tilting of the IVCF was appreciated $<15^{\circ}$ with the IVC, in 12 (4.6\%) patients IVCF tilt was found $>15^{\circ}$. Penetration of the legs in the IVC $>3 \mathrm{~mm}$ was appreciated in $2(0.76 \%)$ patients, inclusion of the superior hook in the wall of the IVC or some other element of the filter was observed in $16(56.1 \%)$ patients, and in $4(1,5 \%)$ patients had evidence of thrombosis of the IVCF. Three hundred and one $(84.5 \%)$ patients were receiving anticoagulation therapy at the time of filter removal, and 55 (154\%) patients were not anticoagulated.

\section{Retrieved IVCF}

A total of 274/356 (76.9\%) filters were successfully removed. Figure 1 shows the distribution of the retrieved IVCF. In eighty-two $(23,0 \%)$ patients, the filters were not removed, in 41 patients $(11,5 \%)$ the retrievable filters were left in as permanent filters (12 patients with advanced neoplasm, 11 patients refused removal, 13 patients were older than 70 years and ongoing filtration was desired due to comorbidities, and five patients were lost to follow up). In twenty-four (6,7\%) patients, the IVCF was not removed since the patients died during the follow-up interval at a mean of $18.9 \pm 9.6$ days (range 2-36 days). Retrieval was not possible in seventeen patients $(4,7 \%)$ due to a tilted $\left(>15^{\circ}\right)$ and embedded filter apex. Table 3 shows the IVCF dwell time. The mean dwell time was $44.8 \pm 170.4$ days, a median of 31 days

Table 2 The main indication for Inferior Vena Cava Filters

\begin{tabular}{|c|c|c|c|c|}
\hline Indications & Direct cause & $n$ & $\mathrm{~N}$ & $\%$ \\
\hline \multirow[t]{3}{*}{ Prevention in high risk patients with DVT } & - EP massive treated with fibrinolysis o thrombectomy & 54 & 120 & 33,7 \\
\hline & - Iliofemoral DVT & 49 & & \\
\hline & $-\mathrm{COPD}+\mathrm{DVT}$ & 17 & & \\
\hline \multirow[t]{4}{*}{ Contraindication for anticoagulation } & - Recente bleeding & 104 & 188 & 52,8 \\
\hline & - Recent surgery & 42 & & \\
\hline & - Brain tumor /Recent stroke & 27 & & \\
\hline & - Severe trauma & 15 & & \\
\hline Recurrence of pulmonary embolism while receiving anticoagulation & & & 48 & 13,4 \\
\hline
\end{tabular}




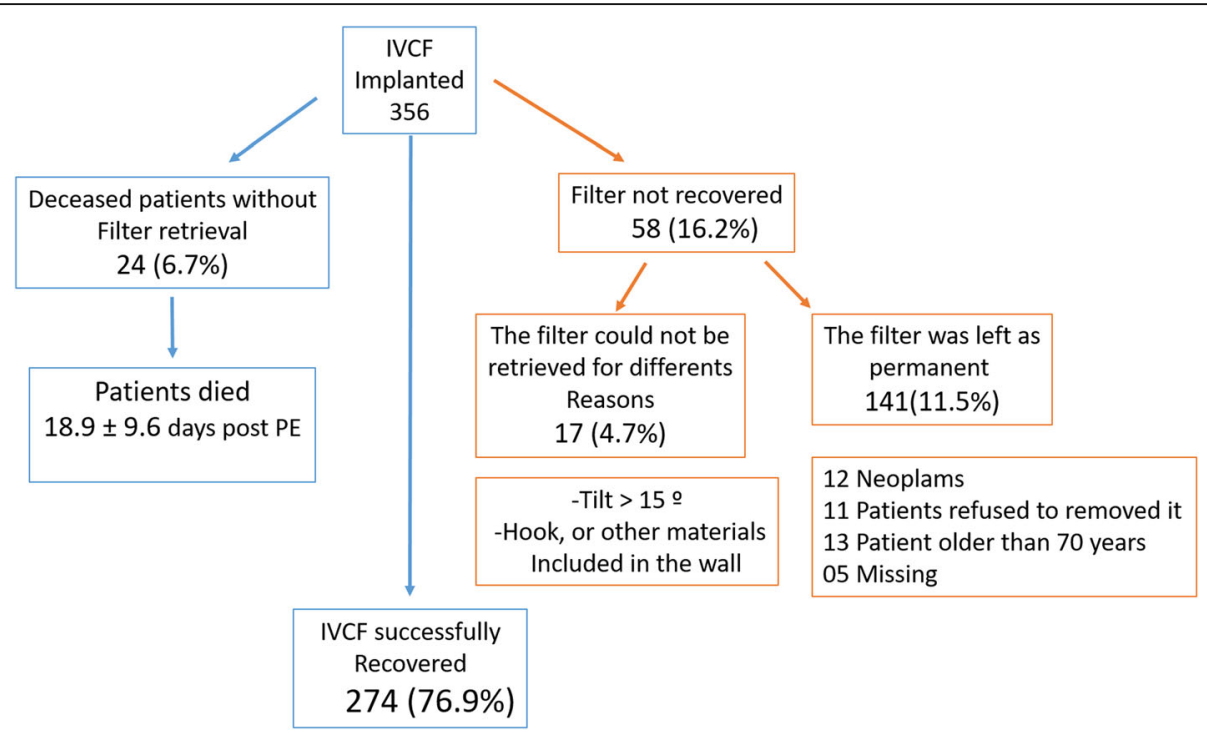

Fig. 1 Diagram showing the distribution of inferior vena cava filters. Filters retrieved successfully and unable to retrieve filters with their causes

(ranging 1-2920 days). Table 4 shows the number and the percentage of each type of filters that were not recovered, as a result of the patients had died, could not be retrieved or because they were left as permanent filters.

\section{Difficulties and complications}

Removal difficulties occur in 26 patients (7.3\%) (mainly related to tilting $>15^{\circ}$ and inclusion of the upper hook or some structure in the wall of the IVC.

Special endovascular maneuvers were performed to retrieve filters with an average of 2.8 maneuvers, with a range of 1-4 additional maneuvers (femoral-jugular double access, Snare-Loop Technique, the Hangman Technique) and repeated attempts at recovery in $9 / 26$ patients, IVCF was recovered with an average of 2.1 attempts (range 1-3). Despite several attempts (average
2.5 and $1-3$ range) in $17 / 26$ patients, IVCF could not be recovered and was left as permanent filters (Fig. 2) (Table 5). Of the IVCF defined as retrievable filters (without patients who died and those who for various reasons were left as permanent filters), the global removal success was $76.96 \%$. When comparing the dwell time of the filters extracted successfully and in which it failed, the average period was $35.2 \pm 15$ days with a median 32 days for the extracted ones versus $65 \pm 56$ days on average with a median of 48 days in the that failed $(p=0.0011)$. IVCF thrombosis was observed in four patients (1.2\%). After fibrinolysis in two patients and thromboaspiration in 2, the filter could be removed without any complications. Complications were found in 12 patients (3.3\%): 6 neck hematomas and 5 groin hematoma, (type I complication) (Filippiadis et al. 2017). Accidental carotid punctured in 1 patient, which

Table 3 Days until the filter was retrieved in each type of filter, either satisfactorily or failed as well as the range (maximum and minimum days for each type of filter)

\begin{tabular}{|c|c|c|c|c|c|c|c|}
\hline \multirow[t]{2}{*}{ Filter (356) } & \multirow[t]{2}{*}{$\mathrm{N}$} & \multirow[t]{2}{*}{$\%$} & \multicolumn{2}{|c|}{ Mean days until retrieval } & \multicolumn{2}{|c|}{ Range days } & \multirow[t]{2}{*}{$p$} \\
\hline & & & Successful & Failed & Min & $\operatorname{Max}$ & \\
\hline Gunther Tulip (Cook) & 160 & 44,9 & $146 / 64,6$ & $2 / 87,5$ & 1 & 2920 & $<0.01$ \\
\hline Optease (Cordis) & 77 & 21,6 & $44 / 29,1$ & $11 / 48,09$ & 12 & 98 & $<0.01$ \\
\hline Celect (Cook) & 49 & 13,7 & $42 / 41,1$ & $2 / 151$ & 19 & 270 & $<0.01$ \\
\hline Aegisy (Lifetech & 33 & 9,2 & $20 / 14,9$ & $1 / 13$ & 11 & 27 & 0.05 \\
\hline Option ELITE (Argon) & 16 & 4,4 & $11 / 32,3$ & $1 / 28$ & 26 & 41 & 0.01 \\
\hline Denali (Bard) & 11 & 3,08 & $8 / 31$ & $0 / 0$ & 26 & 35 & 0.04 \\
\hline ALN Filter (ALN) & 10 & 2,8 & $8 / 32,3$ & $0 / 0$ & 26 & 366 & 0.04 \\
\hline TOTAL & 356 & & & & 1 & 2920 & \\
\hline
\end{tabular}


Table 4 Distribution by type of filter (Successful withdrawal or failure, as well as filters that could not be removed because the patient died during their hospital stay or for various reasons, were left as permanent filters)

\begin{tabular}{|c|c|c|c|c|c|c|c|}
\hline Filter & $\mathrm{N}$ & $\%$ & Successful & Failed & Dead $^{*}$ & Permanent & $p$ \\
\hline Gunther Tulip (Cook) & 160 & 44,9 & $146 / 91,2 \%$ & $2 / 1,2 \%$ & $9 / 5,6 \%$ & $2 / 1,2$ & $<0.01$ \\
\hline Optease (Cordis) & 77 & 21,6 & $42 / 54,5 \%$ & $11 / 14,2 \%$ & $6 / 7,7 \%$ & $17 / 22,0 \%$ & $<0.01$ \\
\hline Celect (Cook) & 49 & 13,7 & $42 / 85,7 \%$ & $2 / 4,0 \%$ & $2 / 4,0 \%$ & $2 / 4,0 \%$ & $<0.01$ \\
\hline Aegisy (Lifetech & 33 & 9,2 & $20 / 60,6 \%$ & $1 / 3,0 \%$ & $3 / 9,0 \%$ & $12 / 36,3 \%$ & $<0.1$ \\
\hline Option ELITE (Argon) & 16 & 4,4 & $11 / 68,7 \%$ & $1 / 6,25 \%$ & $1 / 6,2 \%$ & $4 / 25 \%$ & 0.05 \\
\hline Denali (Bard) & 11 & 3,08 & $7 / 63,6 \%$ & $0 / 0$ & $1 / 9,0 \%$ & $3 / 27,7 \%$ & 0.04 \\
\hline \multirow[t]{2}{*}{ ALN Filter (ALN) } & 10 & 2,8 & $6 / 60 \%$ & 0/0 & $2 / 20$ & $1 / 10 \%$ & 0.04 \\
\hline & 356 & & 274 & 17 & 24 & 41 & \\
\hline
\end{tabular}

* Patients died before inferior vena cava filter was scheduled for retrieval

required compression and admission of $24 \mathrm{~h}$ (type II complication) (Filippiadis et al. 2017). In 276 (77.5\%) patients, fluoroscopy time and Air Kerma were studied (Table 6).

\section{Follow-up}

In $264(74.1 \%)$ patients, follow-up time was $11.3 \pm 3.2$ months after IVCF recovery. All patients were treated with oral anticoagulation or low molecular weight between 6 and 8 months. There were 2 cases of recurrence of PE after IVCF retrieval. Both were documented with pulmonary CT angiography, echocardiography, and biological markers. One of them, occurred when the patient was not anticoagulated, and was classified as a lowintermediate risk for PE and was treated with new oral anticoagulant treatment. The other, a young patient,
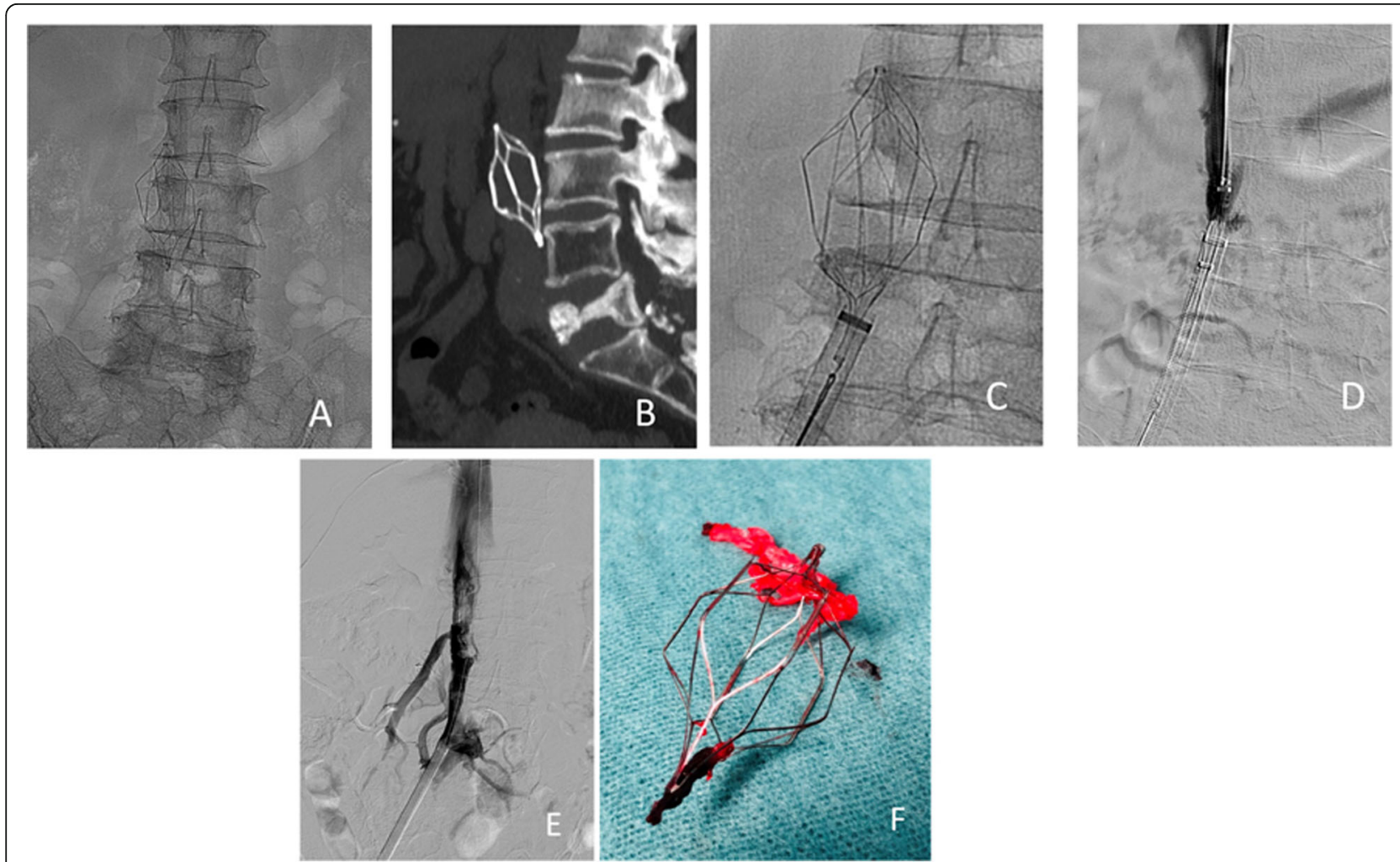

Fig. 2 Example of IVCF retrieval with difficulty. A 61-year-old female patient diagnosed with multiple myeloma. Six years ago she had DVT in her left lower limb. She was treated with unfractionated heparin and had an upper-Gl bleed, and anticoagulants became contraindicated. An Optease filter was implanted infrarenal. a. abdominal x-ray showed the Optease filter in a proper position. $\mathbf{b}$. Abdominal $C T$ with sagittal MPR showed the filter slightly tilted on the vertical axis. c. Femoral access with a $16 \mathrm{Fr}$ sheath and a $25 \mathrm{~mm}$ snare (Amplatz GooseNet snare). After several attempts, it was impossible to recover it. $\mathbf{d}$. Jugular access was made with a $12 \mathrm{~F}$ sheath and a guide was passed through the upper vertex of the filter and with several movements from both accesses, the IVCF was introduced into the sheath and the filter could be recovered. e. Cavography after filter retrieval (shows endothelial alteration). f. The filter recovered with endothelial remains 
Table 5 Main causes of IVCF recovery failure and number retrieval attempts

\begin{tabular}{|c|c|c|c|c|}
\hline Filter & $\mathrm{N}$ & Failed & Reasons for failed & Recovery Attemps \\
\hline \multirow[t]{2}{*}{ Gunther Tulip (Cook) } & 160 & $2 / 1,2 \%$ & -Tilt> $15^{\circ}$, Hook included in IVC wall & 2 \\
\hline & & & - Hook and legs included in IVC wall & 3 \\
\hline \multirow[t]{2}{*}{ Optease (Cordis) } & 77 & $11 / 14,2 \%$ & - Legs and structures included in IVC wall & 2 (5 pats) \\
\hline & & & - Legs and structures included in IVC wall & 1 (6 pats.) \\
\hline \multirow[t]{2}{*}{ Celect (Cook) } & 49 & $2 / 4,0 \%$ & -Tilt> $15^{\circ}$, Hook included in IVC wall & 2 \\
\hline & & & - Tilt> $15^{\circ}$, Hook included in IVC wall & 1 \\
\hline Aegisy (Lifetech) & 33 & $1 / 3,0 \%$ & - Legs and structures included in IVC wall & 1 \\
\hline Option ELITE (Argon) & 16 & $1 / 6,25 \%$ & -Tilt> $15^{\circ}$, Hook included in IVC wall & 2 \\
\hline Denali (Bard) & 11 & $0 / 0$ & - & \\
\hline \multirow[t]{2}{*}{ ALN Filter (ALN) } & 10 & $0 / 0$ & - & \\
\hline & 356 & 17 & & \\
\hline
\end{tabular}

(Pats: Patients)

diagnosed with hematologic disease and hereditary thrombophilia (homologous Leiden Factor V) was decided on the new placement of definitive filter and anticoagulation treatment for life.

\section{Discussion}

The SERVEI-REFiVeC registry is a study of 356 retrievable ICVFs in 355 patients, which gathers the activity of fifteen major Spanish hospitals. This study has limitations since in Spain, there is no consensus, protocol or guidelines accepted by the different societies regarding VTD regarding placement and retrieval of IVCF. Interventional Radiologists are aware of the recommendations of the FDA and other administration to remove all filters as soon as possible, once they are no longer needed. The total recovery rate of FVCI in this study was $76.9 \%$, it might seem low if we compare it with the data from the CIRSE Registry (De Gregorio et al. 2006) in which the recovery rate is 92\%. Other nonmulticenter studies (De Gregorio MA et al.) (Sarosiek et al. 2013) reach 96\% success in recovery. However, the British Society of Interventional Radiology (BSIR) registry (Lee et al. 2015) presents similar or even lower data

Table 6 Fluoroscopy time and Air Kerma data for retrieval procedure (successful and failed filter retrieval)

\begin{tabular}{lllll}
\hline Recovery & & Fluoroscopy time Minutes & Air Kerma mGy & $p$ \\
\hline Successful & Mean & 13,7 & 395,2 & $<0.01$ \\
& SD & 11,6 & 505,7 & \\
& Max & 33,1 & 1796,1 & \\
& Min & 2,5 & 94,7 & \\
Failed & Mean & 41,9 & 1641,7 & $<0.01$ \\
& SD & 11 & 421 & \\
& Max & 64 & 2117,2 & \\
& Min & 25,4 & 1314,9 & \\
\hline
\end{tabular}

(426/514) 66,9\%, other authors such as Sarosiek et al. in 2013 (de Gregorio et al. 2018) in a series of 679 retrievable filters only 58 (8\%) were removed.

The differences can be very important because the study designs are different. In the present SERVEIREFiVeC study, after withdrawing patients which had died 24(6\%), and $41(11.5 \%)$ patients with the initial intention to retrieve the filter, but finally for different reasons or because there is no clear protocol in their hospital, the petitionary clinician decided not to remove the filter. The adjusted retrieval rate of Vena Cava Filters in SERVEI-REFiVeC reaches 94.15\% (291/356). Only in 17 patients $(4.7 \%)$ was attempted for retrieval but was not possible for different reasons.

Several studies have shown that the retrievability of different types and models of filters is similar and there are no significant differences (Sarosiek et al. 2013; Uberoi et al. 2013a; Lyon et al. 2009; Rimon et al. 2009; Pellerin et al. 2008; Uberoi et al. 2013b; Deso et al. 2016; Kuo et al. 2012). The importance of the retrievable filters is recoverability property, because it is a thrombogenic device, that according to various studies provides it limited clinical benefit and can cause complications (Decousus et al. 1998; PREPIC Study Group 2005; Amendola and Acosta 2016).

It seems that the main difficulty for the recovery of these retrievable filters is the tilting and the embedded apex which may result in fibrosis or endothelialization of the device components into the wall (Uberoi et al. 2013a; Lyon et al. 2009). These factors could be prevented by the operator by improving the implantation technique, and the dwell time of the device. It is important an advanced technique in the implantation of the filter, avoiding tilting $>15^{\circ}$. On the other hand, the FDA recommends the removal of the filters as soon as possible when vena cava interruption is no longer needed. This logical recommendation, together with the 
operator's responsibility, is to suggest the referring physician and the patient retrieve the filter as soon as possible and avoid retrievable procedures with long dwelling time which may present more difficulty and possible complications.

The advanced skills of the operator must not be only evident in the implantation of the filter, but also be able to manage different devices and additional retrieval maneuvers (Iliescu and Haskal 2012; Desai et al. 2017). In this study, additional maneuvers were used in $33(9.2 \%)$ patients. Despite these additional maneuvers, half of the cases (17 patients / 4.7\%) the filters could not be removed.

Prolonged filter dwell time has been associated with a more difficult recovery of the filter, and an increase in complications secondary to the retrieval procedure. The complications include: device fracture, migration, organ penetration by device components, and an elevated risk of thrombosis / DVT (Andreoli et al. 2014). MAUDE (Manufacturer and User Facility Device Experience) (White et al. 2013) has published a high rate of complications in the handling of retrievable filters, which has led the FDA in this same year to do a serious communication insisting to withdraw the FVCI as soon as possible. However, the main filter recovery records do not reveal significant and serious complication rates (Sarosiek et al. 2013; Uberoi et al. 2013a; Deso et al. 2016). In this study, complications related to the access route in the jugular vein were found, the most important an accidental puncture of the carotid artery. There was also no relationship between the difficulties of IVCF recovery and the filter dwell time.

Recent studies have questioned the efficacy of IVCF (Dalen and Stein 2013). Some studies have been pointed out the controversial role of IVCF in the treatment of the VTD. The existence of great variability in the use of filters between hospitals with similar indications of $0 \%$ to $38 \%$ is known (Prasad et al. 2013). Some authors doubt the effectiveness of IVCF in the protection against PE since in a series of 504 patients with PE and IVCF $7.8 \%$ presented recurrence of PE despite the filter (de Gregorio et al. 2018; Kearon et al. 2012). The guidelines of the American College of Chest Physicians (ACCP) and the European Society of Cardiology (ESC) in their recommendations reserve the use of IVCF for the failure and/or contraindication of anticoagulation (Konstantinides et al. 2019; Kearon et al. 2016).

The PREPIC 1 study (Decousus et al. 1998) reinforced by the PREPIC 2 study, (PREPIC Study Group 2005) based on IVCF, initially it decreases PE but increases the rate of DVT and does not influence the mortality of VTD. Current guidelines do not recommend IVCF in anticoagulated patients with VTD (Recommendation 1B) (Dalen 2012).
Even though retrievable filters have largely replaced permanent filters, there is still not enough clinical evidence to increase IVCF indications and modify current guidelines (Uberoi et al. 2013a). The use of a retrievable IVCF with a prompt removal is theoretically consistent with the conclusions of both PREPIC studies (Decousus et al. 1998; PREPIC Study Group 2005). Recoverable filters could potentially be effective in the prevention of life-threatening PE in the short-term. IVCF should be removed as soon as possible when their presence is no longer needed, and avoid filter-related complications including long-term post-thrombotic syndrome. In this study, the 2016 ACCP filter guidelines (Kearon et al. 2016) were closely followed and the indications for filter placement were absolute in $66.2 \%$, in contrast to the CIRSE Registry where absolute indications were only 40\% (Uberoi et al. 2013a).

Retrievable IVCF has demonstrated efficacy in patients with unstable PE (Dalen and Stein 2016; Stein et al. 2012). In patients with unstable PE, hospital mortality was $18 \%$ in patients with fibrinolytic therapy alone, while hospital mortality was reduced to $7.6 \%$ when IVCF was used $(p<0001)$ (Stein et al. 2012). However, despite the big difference in the number of filters implanted per capita in the US versus Europe, the overall death rate from $\mathrm{PE}$ in both populations remains similar (Uberoi et al. 2013a).

There are important limitations of this study, even though the study was supported by SERVEI, only 15 hospitals participated, and Spain has a total of 118 hospitals with IR (De Gregorio and Urbano 2017). The number of participants was small and does not resemble the absolute truth of the implantation of IVCF in Spain. In our opinion, there are too many IVCF left as permanent filters (41/11.5\%). The involvement of the interventional radiologists in the decision to remove or leave the IVCF as permanent is unknown. However, the study objective was not to show the retrieved filters but implanted filters and their possibility of recovery, which shows us a real situation within a small sample. A guide or clinical consensus for the management of IVCF should be promoted from the scientific societies regarding VTD. Finally, it would be necessary to perform a multicenter, and multinational registry in Europe to determine the exact use of IVCF and their retrieval rate.

\section{Conclusion}

In conclusion, IVCF retrieval was achieved $>75 \%$ in a cohort with no major procedural complications. IVCF tilting and embedded apex was associated with failure of filter removal in less than $5 \%$ of cases. This paper does not demonstrate a good correlation between the difficulty of the IVCF recovery and the dwell time. The global retrieval rate was of $76.9 \%$, however the adjusted 
retrieval rate was of $94.15 \%$ comparable with recent studies. This study demonstrates that the retrieval procedure of IVCF is controlled by the clinician and not by the interventional radiologist.

\section{Abbreviations}

ACCP: American College of Chest Physicians; BSIR: British Society of Interventional Radiology; DVT: Deep vein thrombosis; ESC: European Society of Cardiology; IVCF: Inferior vena cava filters; MAUDE: Manufacturer and User Facility Device Experience; PE: Pulmonary embolism; SERVEl: Spanish Society of Vascular and Interventional Radiology; VTD: Venous thromboembolic disease

\section{Acknowledgments}

Not applicable.

\section{Authors' contributions}

MAdG, JAG, JU designed the study. MAdG, JAG, JU, IDL JJM, EV, ALM, and JBS made the acquisition and analysis of the data. MAdF, WTK, JG draft the work. MAdG, AIF, SS, DJ revised the manuscript. The authors read and approved the final manuscript.

\section{Funding}

This study was no supported by any funding.

\section{Availability of data and materials}

The data used and/or analyzed during the current study are available from the corresponding author on reasonable request.

\section{Ethics approval and consent to participate}

All procedures performed in studies involving human participants were following the ethical standards of the institutional and/or national research committee and with the 1964 Helsinki declaration and its later amendments or comparable ethical standards.

\section{Consent for publication}

Consent for publication was obtained for every person's data included in the study.

\section{Competing interests}

The authors declare that they have no competing interests.

\section{Author details}

'Hospital Universitario Lozano Blesa, Universidad de Zaragoza, Zaragoza, Spain. ${ }^{2}$ Hospitales Vithas, Madrid, Spain. ${ }^{3}$ Hospital Universitario La Princesa, Madrid, Spain. ${ }^{4}$ Hospital Universitario Carlos Haya, Malaga, Spain. ${ }^{5}$ Hospital Rio Hortega, Valladolid, Spain. ${ }^{6}$ Hospital de Basurto Hospital, Bilbao, Spain. ${ }^{7}$ Hospital Universitario Miguel Servet, Zaragoza, Spain. ${ }^{8}$ Grupo Investigación Técnicas Mínimamente Invasivas (GITMI), Zaragoza, Spain. ${ }^{9}$ Hospital Universitario Austral, Buenos Aires, Argentina. ${ }^{10}$ Hospital Ramón y Cajal, Madrid, Spain. "Department of Radiology, Stanford University Medical Center, Stanford, CA, USA. ${ }^{12}$ Hospital Ramón y Cajal and Universidad de Alcalá (IRYCIS), Madrid, Spain.

Received: 5 January 2020 Accepted: 17 March 2020

Published online: 18 May 2020

\section{References}

Amendola MF, Acosta GA (2016) Inferior Vena Cava Filter Reporting to the MAUDE Database: Impact of a Governmental Warning. J Vasc Surg 63:92-93 Andreoli JM, Lewandowski RJ, Vogelzang RL, Ryu RK (2014) Comparison of complication rates associated with permanent and retrievable inferior vena cava filters: a review of the MAUDE database. J Vasc Interv Radiol 25:11811185

Athanasoulis CA, Kaufman JA, Halpern EF, Waltman AC, Geller SC, Fan CM (2000) Inferior vena caval filters: review of a 26-year single-center clinical experience. Radiology. 216:54-66

Dalen JE (2012) Thrombolytics and vena cava filters decrease mortality in patients with unstable pulmonary embolism. Am J Med 125(5):429-430
Dalen JE, Stein PD (2013) Are vena cava filters effective in the treatment of pulmonary embolism? Am J Med 126:851-852

Dalen JE, Stein PD (2016) Is there a subgroup of PE patients who benefit from inferior vena cava filters? J Am Coll Cardiol 67(9):1036-1037

De Gregorio MA, Gamboa P, Bonilla DL, Sanchez M, Higuera MT, Medrano J, Mainar A, Lostalé F, Laborde A (2006) Retrieval of Gunther tulip optional vena cava filters 30 days after implantation: a prospective clinical study. J Vasc Interv Radiol 17:1781-1789

de Gregorio MA, Guirola JA, Serrano C, Figueredo A, Kuo WT, Quezada CA, Jimenez D (2018) Success in optional vena cava filter retrieval. An analysis of 246 patients. Arch Bronconeumol 54:371-377

De Gregorio MA, Urbano J (2017) SERVEl, 30 años después. Watson CME, Zaragoza

Decousus H, Leizorovicz A, Parent F, Page Y, Tardy B, Girard P et al (1998) Clinical trial of vena caval filters in the preventionof pulmonary embolism in patients with proximaldeep vein thrombosis: Prévention du Risqued'Embolie Pulmonaire par interruption cave study group. N Engl J Med 338:409-415

Desai KR, Pandhi MB, Seedial SM, Errea MF, Salem R, Ryu RK, Lewandowski RJ (2017) Retrievable IVC Filters: comprehensive review of device-related complications and advanced retrieval techniques. Radiographics. 37:12361245

Deso SE, Idakoji IA, Kuo WT (2016) Evidence-based evaluation of inferior vena cava filter complications based on filter type. Semin Intervent Radiol 33:93-100

Filippiadis DK, Binkert C, Pellerin O, Hoffmann RT, Krajina A, Pereira PL (2017) Cirse quality assurance document and standards for classification of complications: the Cirse classification system. Cardiovasc Intervent Radiol 40:1141-1146

Food and Drug Administration. Inferior vena cava (IVC) filters: initial communication: risk of adverse events with long term use. Posted online August 9, 2011. Available at: http://www.fda.gov/Safety/MedWatch/ SafetyInformation/SafetyAlertsforHumanMedicalProducts/uc.m221707.htm

Iliescu B, Haskal ZJ (2012) Advanced techniques for removal of retrievable inferior vena cava filters. Cardiovasc Intervent Radiol 35:741-750

Kearon C, Akl EA, Comerota AJ, Prandoni P, Bounameaux H, Goldhaber SZ, Nelson ME et al (2012) Antithrombotic therapy for VTE disease: Antithrombotic Therapy and Prevention of Thrombosis, 9th ed: American College of Chest Physicians Evidence-Based Clinical Practice Guidelines. Chest 14:419-496

Kearon C, Akl EA, Ornelas J, Blaivas A, Jimenez D, Bounameaux H, Huisman M et al (2016) Antithrombotic therapy for VTE disease: CHEST guideline and expert panel report. Chest. 149(2):315-352

Konstantinides SV, Meyer G, Becattini C, Bueno H, Geersing GJ, Harjola VP, Huisman MV, Humbert M, Jennings CS, Jiménez D, et al 2019 ESC guidelines for the diagnosis and management of acute pulmonary embolism developed in collaboration with the European Respiratory Society (ERS) European heart journal (2019)

Kuo WT, Cupp JS, Louie JD, Kothary N, Hofmann LV, Sze DY, Hovsepian DM (2012) Complex retrieval of embedded IVC filters: alternative techniques and histologic tissue analysis. Cardiovasc Intervent Radiol 35:588-597

Lee MJ, Valenti D, de Gregorio MA, Minocha J, Rimon U, Pellerin O (2015) The CIRSE retrievable IVC filter registry: retrieval success rates in practice. Cardiovasc Intervent Radiol 38:1502-1507

Lyon SM, Riojas GE, Uberoi R, Patel J, Lipp ME, Plant GR, De Gregorio MA et al (2009) Short-and long-term retrievability of the Celect vena cava filter: results from a multiinstitutional registry. JVIR. 20(11):1441-1448

Monreal M, Mahé I, Bura-Riviere A, Prandoni P, Verhamme P, Brenner B, Wells PS, Di Micco P, Bertoletti L (2015) Pulmonary embolism: epidemiology and registries. Presse Med 44:377-383

Morales JP, Li X, Irony TZ, Ibrahim NG, Moynahan M, Cavanaugh KJ Jr (2013) Decision analysis of retrievable inferior vena cava filters in patients without pulmonary embolism. J Vasc Surg Venous Lymphat Disord 1:376-384

Pattullo CS, Barras M, Tai B, McKean M, Donovan P (2016) New Oral anticoagulants (NOACS) - appropriateness of prescribing in real- world setting. Intern Med J 46:812-818

Pellerin O, Barral FG, Lions C, Novelli L, Beregi JP, Sapoval M (2008) Early and late retrieval of the ALN removable vena cava filter:results from a multicenter study. CVIR. 31(5):889-896

Prasad V, Rho J, Cifu A (2013) The inferior vena cava filter. How could a medica device be so well accepted without evidence of efficacy? JAMAIntern Med 173:493-495

PREPIC Study Group (2005) Eight-year follow-up of patients with permanent vena cava filters in the prevention of pulmonary embolism: the PREPIC 
(prevention du Risque d'Embolie Pulmonaire par interruption cave) randomized study. Circulation. 112:416-422

Proctor MC, Greenfield LJ (2008) Form and function of vena cava filters: how do optional filters measure up? Vascular. 16:10-16

Reddy S, Lakhter V, Zack CJ, Zhao H, Chatterjee S, Bashir R (2017) Association between contemporary trends in inferior vena cava filter placement and the 2010 US Food and Drug Administration advisory. JAMA Intern Med 177: $1373-1374$

Rimon U, Bensaid P, Golan G, Garniek A, Khaitovich B, Dotan Z, Konen E (2009) Optease vena cava filter optimal indwelling time and retrievability. CVIR. 34(3):532-535

Sarosiek S, Crowther M, Sloan M (2013) Indications, complications, and management of inferior cava filters. JAMA Intern Med 173:513-517

Sociedad Española Radiología Intervencionista (SERVEI), estudios y registros; Avalaible at: https://estudios.watsoncme.com/refivec/site/index. Accessed February 29, 2020

Stein PD, Kayali F, Olson RE (2004) Twenty-one-year trends in the use of inferior vena cava filters. ArchIntern Med 164:1541-1545

Stein PD, Matta F, Keyes DC, Willyerd GL (2012) Impact of inferior vena cava filters on in-hospital case fatality rates from pulmonary embolism. Am J Med $125: 478-484$

Uberoi R, Ross Tapping C, Chalmers N, Allgar V (2013b) British Society of Interventional Radiology (BSIR) inferior vena cava (IVC) filter registry. CVIR. 36: 1548-1561

Uberoi R, Tapping CR, Chalmers N, Allgar V (2013a) British Society of Interventional Radiology (BSIR) inferior vena cava (IVC) filter registry. Cardiovasc Intervent Radiol 36:1548-1561

von Elm E, Altman DG, Egger M et al (2007) The strengthening the reporting of observational studies in epidemiology (STROBE) statement: guidelines freporting observational studies. Lancet 370:1453-1457

Wadhwa V, Trivedi PS, Chatterjee K, Tamrazi A, Hong K, Lessne ML, Ryu RK (2017) Decreasing utilization of inferior vena cava filters in post-FDA warning era: insights from 2005 to 2014 Nationwide inpatient sample. J Am Coll Radiol 14:1144-1150

White RH, Geraghty EM, Brunson A et al (2013) High variation between hospitals in vena cava filter use for venous thromboembolism. JAMA Intern Med 173: $506-512$

Yunus TE, Tariq N, Callahan RE, Niemeyer DJ, Brown OW, Zelenock GB, Shanley CJ (2008) Changes in inferiorvena cava filter placement over the past decade at a large community based academic health center. J Vasc Surg 47:157-165

\section{Publisher's Note}

Springer Nature remains neutral with regard to jurisdictional claims in published maps and institutional affiliations.

\section{Submit your manuscript to a SpringerOpen ${ }^{\circ}$ journal and benefit from:}

- Convenient online submission

- Rigorous peer review

- Open access: articles freely available online

- High visibility within the field

- Retaining the copyright to your article

Submit your next manuscript at $\boldsymbol{\nabla}$ springeropen.com 